\title{
THE ATTEMPT OF THE LOW-CYCLE FATIGUE LIFE DESCRIPTION OF CHOSEN CREEP-RESISTANT STEELS UNDER MECHANICAL AND THERMAL INTERACTIONS
}

\begin{abstract}
The study focuses on the problem of determination of low-cycle fatigue properties for the chosen group of creep-resistant steels used in the power and chemical industries. It tries to find the parameter which would describe well the fatigue life and take into account mechanical loads and temperature. The results of LCF tests have been presented in the paper. New parameter P has been introduced. This parameter joins a plastic strain range, a stress range and temperature. The fatigue life has been predicted versus parameter P. The comparison of the predicted and observed values of fatigue life shows the agreement between these values. The method of fatigue life prediction formulated in this way is expected to describe the behavior of materials under thermo-mechanical fatigue.
\end{abstract}

Keywords: low-cycle fatigue, high temperatures, fatigue life prediction, creep-resistant steels

\section{Introduction}

The onset of defects in some parts of equipment operating at elevated temperatures and subject to mechanical and thermal interactions is a complex process. These defects may result from creep or fatigue as well as they may be caused by corrosion or erosion of material. The result of a combination of these is often the onset of cracks whose development constitutes a major degradation of performance of these parts and may cause failure of the equipment with serious consequences.

There are studies on creep processes of materials, their durability and methods of assessing the degree of material damage caused by long-term effects of load and temperature [1-5]. Many studies concentrate on the issue of initiation and growth of cracks both at room temperature and at elevated temperatures [1,6-9]. They concern crack development with loads either fixed or varying over time. There are also studies devoted to the problem of formation of cracks under fatigue conditions occurring at elevated temperatures, but these are generally for specific materials, whose properties are determined for selected temperature ranges [10-14].

To specify useful for designers fatigue life properties, well-known methods of Manson, Coffin, Östergren and others [10-17] are often used, which determine the fatigue life, usually by the use of such variables as the range of total, elastic and plastic strains and the range of stress, or their maximum or amplitude values. The properties are then provided for fixed temperatures.
The standards used by designers of equipment operating at elevated temperatures suggest taking fatigue into account by assessing its effects on the basis of Wöhler curves. These curves, for selected material groups used in the energy sector, are defined by the tensile strength [18]. There are still no fatigue life criteria that take into account simultaneously the effect of variable temperature and mechanical load. Fatigue properties determined under isothermal conditions are most frequently used to assess the intensity of fatigue caused by loads and temperature in this case.

The study focuses on the determination of low-cycle fatigue properties for the particular materials used in the power and chemical industries. It tries to find the parameter which would describe well the fatigue life and take into account mechanical loads and temperature. The method of determining fatigue life formulated in this way is expected to describe the behavior of materials under thermo-mechanical fatigue [19-24].

\section{Materials for research}

Materials used at elevated temperatures, characterized by high resistance to creep and corrosion have been examined. These include steels X15CrNiSi18-8, X16CrNi25-20 and X50CrMnAl12-16-2. Steels have austenitic structure. Steel X50CrMnA112-16-2 was designed for use at elevated temperatures some years ago and in this work its properties were determined to compare it with conventional materials. Table 1 shows the chemical composition of the materials considered.

\footnotetext{
SILESIAN UNIVERSITY OF TECHNOLOGY, INSTITUE OF METALS TECHNOLOGY, KATOWICE, POLAND 
Chemical composition of the tested steels

\begin{tabular}{|c|c|c|c|}
\hline \multirow{2}{*}{} & \multicolumn{3}{|c|}{ Steel grade } \\
\cline { 2 - 4 } & X15CrNiSi18-8 & X16CrNi25-20 & X50CrMnAl12-16-2 \\
\hline $\mathrm{C}$ & 0,15 & 0,06 & 0,52 \\
\hline $\mathrm{Mn}$ & 1,42 & 1,45 & 16,02 \\
\hline $\mathrm{Cr}$ & 18,69 & 23,12 & 12,10 \\
\hline $\mathrm{Si}$ & 1,35 & 0,63 & 0,40 \\
\hline $\mathrm{P}$ & 0,033 & 0,03 & 0,02 \\
\hline $\mathrm{S}$ & 0,022 & 0,007 & 0,16 \\
\hline $\mathrm{Al}$ & - & - & 2,0 \\
\hline $\mathrm{Ni}$ & 8,88 & 17,78 & - \\
\hline $\mathrm{Cu}$ & 0,18 & 0,1 & - \\
\hline $\mathrm{V}$ & - & - & 0,3 \\
\hline $\mathrm{Mo}$ & - & - & 0,2 \\
\hline
\end{tabular}

They have been consistently tested in a supersaturated state. By this treatment all the materials for research have austenitic structure, and were prepared as $20 \mathrm{~mm}$ diameter rods, from which the test pieces for fatigue testing have been made. The specimens had $25 \mathrm{~mm}$ gage length; $12 \mathrm{~mm}$ diameter with M18 threads into chucks each end. The specimens prepared were subject to fatigue tests carried out at room temperature and nominated high temperatures.

\section{Fatigue test conditions and results of the fatigue tests}

Fatigue tests were carried out using a servohydraulic MTS system, equipped with induction heating for the test pieces. Total strain was controlled during the tests using a strain sensor with quartz rods, the ends of which were in contact with the test piece. The tests were performed at $600^{\circ} \mathrm{C}, 300^{\circ} \mathrm{C}$ and room temperatures. Such parameters as temperature, total strain range, stress range and stress amplitude in saturation state, elastic and plastic strain range and the number of cycle to failure were determined. Based on these, fatigue diagrams for each temperature can be produced.

The aim of this part of the study was to evaluate the effect of temperature on the fatigue properties of materials in the lowcycle fatigue range. The tests performed have shown a significant effect of temperature on the fatigue life in the temperature range tested.

\section{Modified method of the fatigue life description at elevated temperatures}

The methods that are usually used for recognizing fatigue properties of the materials, such as Manson-Coffin or Östergren criteria for instance enable qualitative description of the effect of temperature on mechanical properties of materials, which are predicted to use in the conditions, when temperature could change in defined range. The tests made it also possible to compare the fatigue properties of the materials in terms of their suitability for use at elevated temperatures. However, taking into account the fatigue life assessment, the application of this kind of approach in the design of machines and equipment is possible only to a limited extent, as there are problems in assessing the durability of components working in fixed temperatures under mechanical loads. The use of fatigue properties derived under isothermal conditions is questionable in the case of simultaneous interaction of changing temperature and strain. The question is whether or not it is possible to formulate such criteria, which would take into account both the size of the variable load and the variable temperature at which the fatigue process takes place.

The impact of elevated temperatures under conditions of low cycle fatigue of creep-resisting steel is on two important processes in these materials. The first is the process of plastic deformation, the magnitude of which under these conditions can be measured by the width of the hysteresis loop. While the temperature increases the width of the hysteresis loop increases, due to increased susceptibility of materials to plastic deformation, neglecting effects of cyclic hardening of materials. The plastic strain range growth is generally connected with the fatigue life decrease. The second is the reconstruction of the material structure during the deformation process, resulting in the formation of fatigue cracks. The increase in temperature usually accelerates this process and reduces the fatigue life as well.

The synergic effect of the factors affecting the fatigue life, namely plastic strain and temperature, appears to be sufficient justification for an attempt to introduce a parameter that would include both of them. As well important as plastic strain range and temperature is a range of stress. This range increases or decreases as a result of cyclic hardening or softening. The parameter which includes plastic strain range and stress range is a product of them and it can be treated as the measure of an energy of plastic deformation, and it is used as the fatigue life criterion as well. Such a factor introduces a quantity associated with the dissipated energy in the material during each fatigue cycle $-\Delta \varepsilon_{p} \Delta \sigma$. Similarly, the magnitude of plastic strain and stress is treated in the Östergren criterion where the number of cycles to failure is introduced as a function of the variable $-\Delta \varepsilon_{p} \sigma_{\max }[15,16]$.

The fatigue life criterion-parameter, the verification of which is the purpose of this study, recognizes the interdependence of the three quantities determining fatigue in a way which takes into account the amount of energy responsible for the degree of damage of the material and the impact of the temperature on the fatigue life. The factor value, which indicates the number of cycles to failure, was adopted in the following form:

$$
P=\Delta \varepsilon_{p} \Delta \sigma T
$$

The results of fatigue tests were then used to describe the fatigue life as a function of $\mathrm{P}$ parameter defined by equation (1). The following diagrams (Figs. 1-3) show the relationships between $\mathrm{P}$ and the number of cycles to failure for the $\mathrm{X} 15 \mathrm{CrNi}$ Si18-8, X16CrNi25-20 and X50CrMnAl12-16-2 steels. In the diagrams in Fig. 4, the results of the tests are shown for each of the materials in the range over which test results can be repre- 


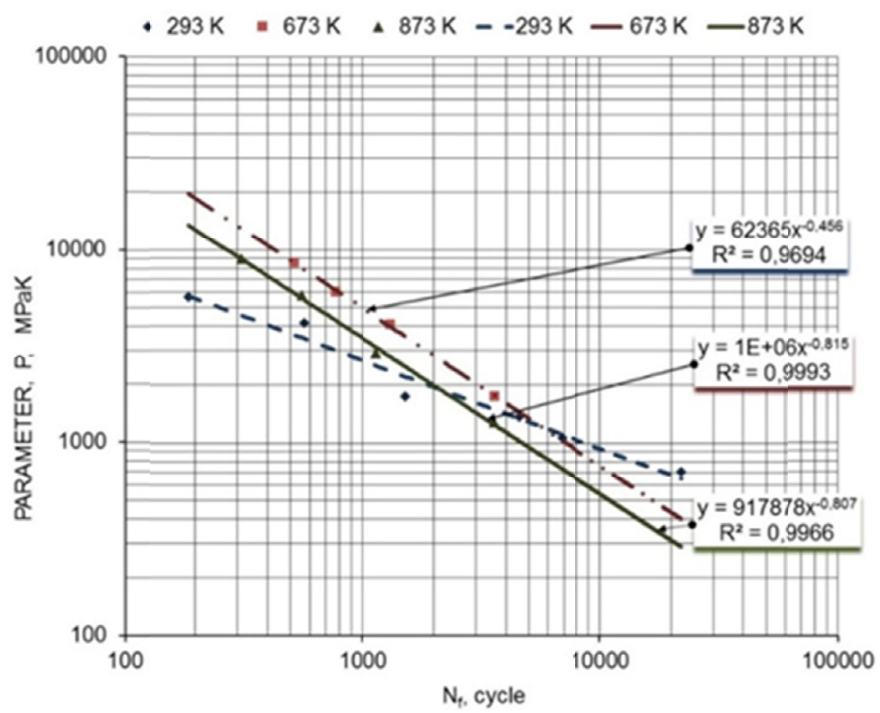

Fig. 1. Fatigue diagram X15CrNiSi18-8 steel at different temperatures

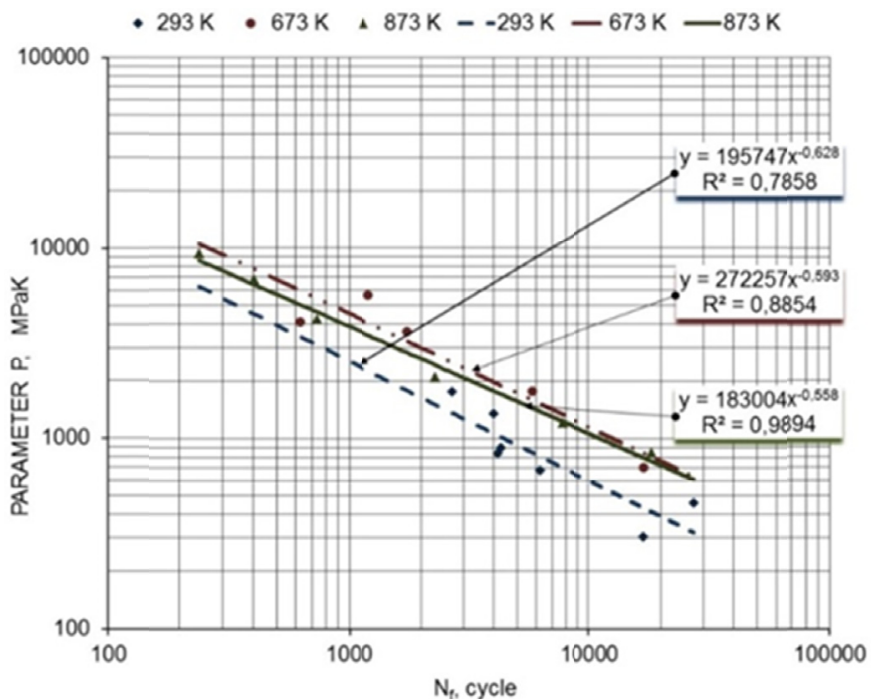

Fig. 2. Fatigue diagram X16CrNi25-20 steel at different temperatures

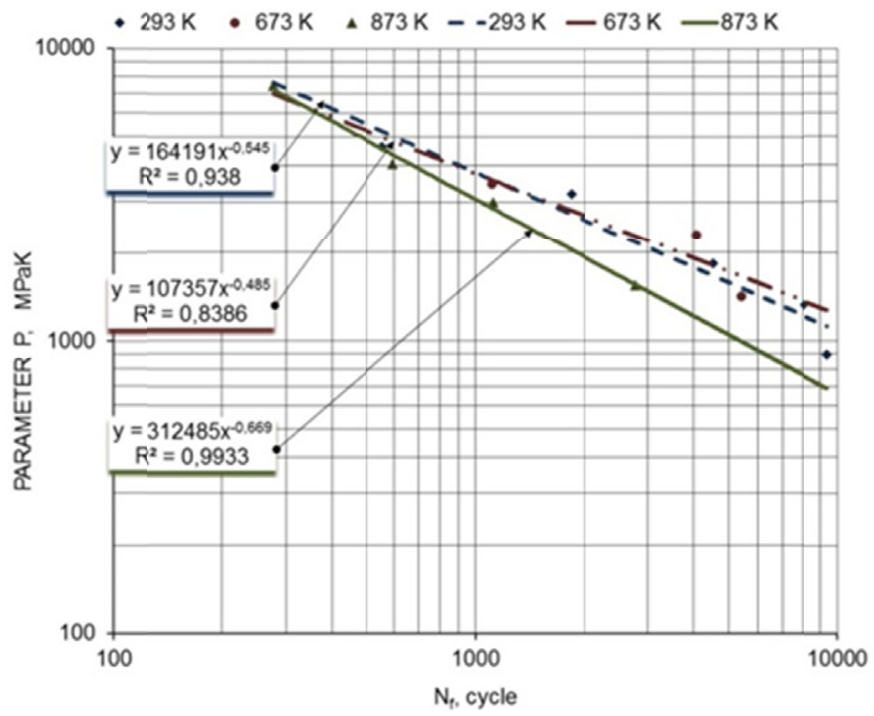

Fig. 3. Fatigue diagram X50CrMnAl12-16-2 steel at different temperatures sented by a single equation for each steel. Each line has been determined taking into account all points of each steel - points for different temperature determine the course of the collective fatigue diagram. In the study, the results were represented in the form:

$$
P=C N^{n}
$$

Derived coefficients of correlation show the validity of such an approach. In the Fig. 5 the collective diagram has been worked out for all points taken from the tests. The Fig. 5 contains points for different steels and different temperatures, the diagram is collective for all temperatures and all steels. Both the coefficient of correlation and the width of the band (which borders are defined as 2,5N and $N / 2,5$ in relation to the predicted fatigue

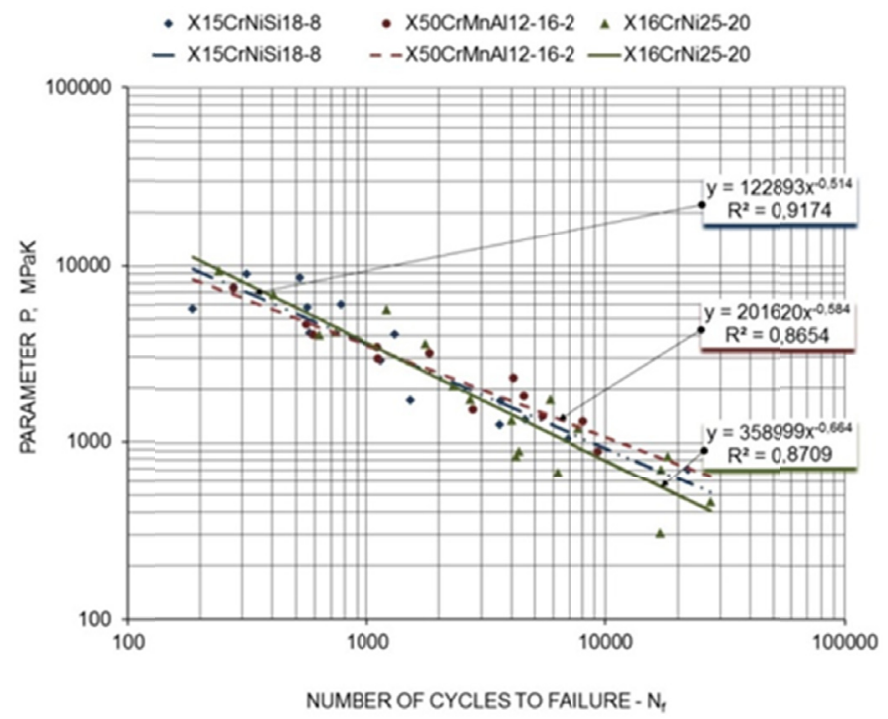

Fig. 4. Collective fatigue diagrams; X15CrNiSi18-8, X16CrNi25-20, X50CrMnAl12-16-2 steels

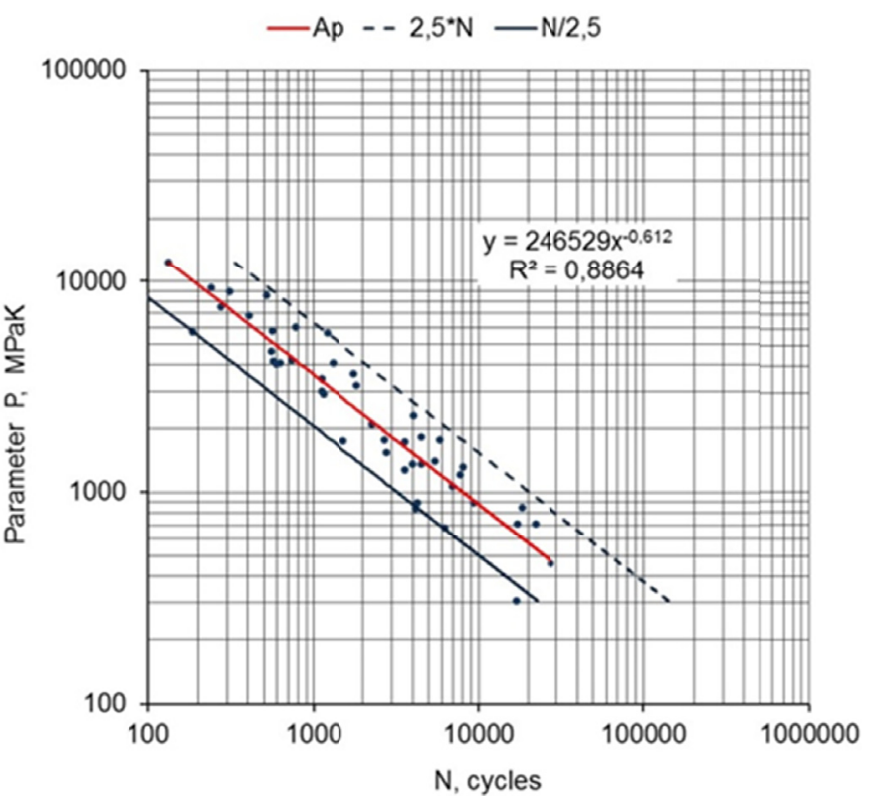

Fig. 5. Collective fatigue diagram; X15CrNiSi18-8, X16CrNi25-20, X50CrMnAl12-16-2 steels; linear approximation in red 
life $N$ ) show the possibility of the use of simple formulas (1) and (2) to describe the fatigue life of the materials considered for the range of temperatures of the tests which were described.

After that the comparison has been made of the observed and predicted fatigue life (Figs. 6,7). Fig. 6 shows the band (which borders are defined as $2,5 N_{a}$ and $N_{a} / 2,5$ in relation to the ideal situation, when predicted fatigue life $-N_{p}$ equals the observed one $-N_{a}$ ). The line which represents an linear approxi-

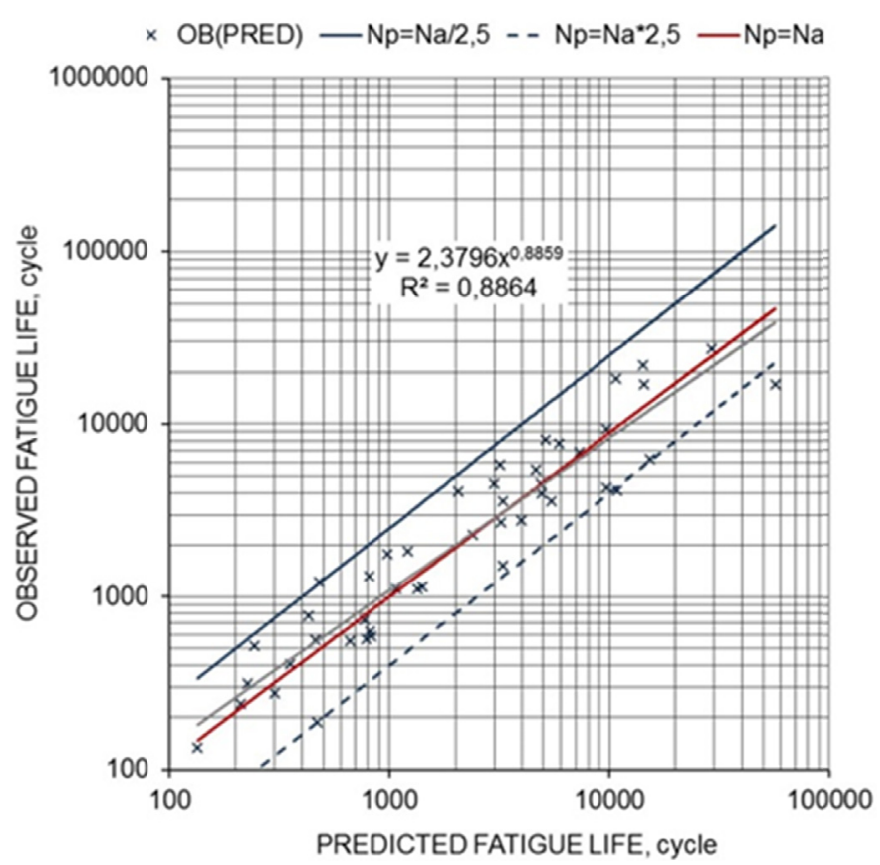

Fig. 6. Comparison of results from the experiment and the model; X15CrNiSi18-8, X16CrNi25-20, X50CrMnAl12-16-2 steels, linear approximation of the experimental versus predicted life has been shown in gray color

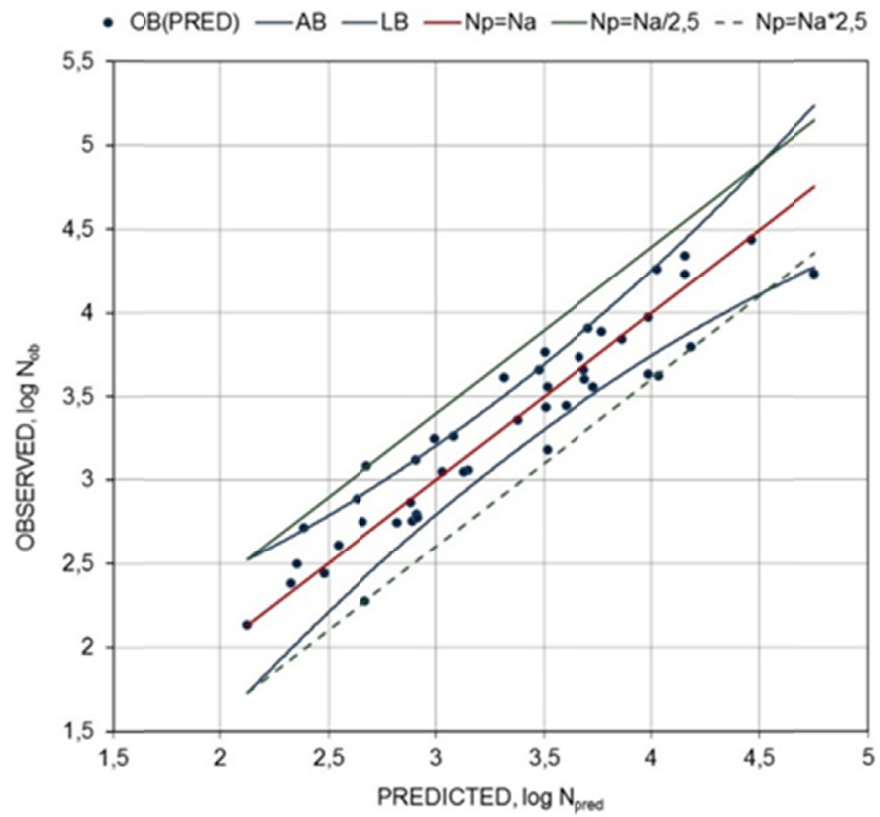

Fig. 7. Comparison of results from the experiment and the model; X15CrNiSi18-8, X16CrNi25-20, X50CrMnA112-16-2 steels, and 95\% confidence intervals of estimated values indicated in blue mation has been shown in this figure as well. Fig. 7 represents the similar characteristics, but logarithm values of the predicted and observed fatigue lifes have been shown in the axis. The $95 \%$ confidence intervals of estimated values have been calculated and additionally introduced in this Fig. 7.

\section{Discussion}

The approach presented in the study towards fatigue life under low-cycle fatigue is an attempt to formulate a factor linking various variables in a way that allows its use in forecasting the fatigue life dependent on the conditions of fatigue process using characteristics that were described for the group of materials. The comparison of the predicted and observed fatigue life shows a good agreement between these values (Figs. 6,7) and narrow band of $95 \%$ intervals of estimated values. It seems that such an approach would be useful for technical applications, when fatigue life would be predicted for materials in question. The usefulness of such fatigue life description at this stage of research should be of course limited to the intervals of the fatigue parameter which were used in the experiments - total strain range and temperature. The total strain ranges in the experimental part of the work should be within the range of 0,005 to 0,023 . The temperature should be within the range of $293 \mathrm{~K}$ to $873 \mathrm{~K}$. In the future research the ranges of test parameters will be extended and the ranges of application of the formula (1) will be more precisely defined.

The simple formula (1) for fatigue factor $P$ containing the temperature at which the fatigue process is taking place and load variables that have been successfully incorporated into the study, considering the assumptions and limitations, has a structure that could possibly apply to other cases not only of isothermal fatigue.

It is not simple to describe the properties of thermo-mechanical fatigue including all the relations between the variables of the mechanical strain cycles and temperatures, both in relation to the ranges of temperature, strain and stress, nature of cycles of mechanical and thermal load tests and the shift in the phase of the cycle of temperature and mechanical load. But it seems to be possible to use the factor $P$ that combines the various variables of the low-cycle fatigue process, for the fatigue life prediction of the chosen material as a simple formula. However, the question should be raised as to how the temperature $T$ should be treated in formula (1) with respect to its variation during thermo-mechanical fatigue. The first step to solve the problem was made in the work [24]. As the first approximation it was assumed that $T$ in formula (1) under thermo-mechanical fatigue could be represented by the maximum temperature of the fatigue cycle [24].

The results presented in this paper conclude the research phase on a selected group of creep-resisting steels in low-cycle isothermal fatigue conditions. The next stage of the research comprises thermo-mechanical fatigue tests, the results of which, in subsequent publications, will be compared with these results of studies carried out at constant temperatures. 


\section{Acknowledgements}

This paper was created with the financial support of Association of Graduates of the Faculty of Metallurgy and Materials Engineering of Silesian University of Technology, Poland.

\section{REFERENCES}

[1] G.A. Webster, R.A. Ainsworth, High Temperature Component Life Assessment, Chapman \& Hall, 1994 London.

[2] FITNET Report (European Fitness-for-service Network) Edited by M. Kocak, S. Webster, J.J. Janosch, R.A. Ainsworth, R. Koers, Contract No. G1RT-CT-2001-05071, 2006.

[3] Nuclear Electric Ltd, Assessment Procedure for the High Temperature Response of Structure, Proc. R5 Issue 2, UK,1997.

[4] A. Hernas, Żarowytrzymałość stali i stopów, Wydawnictwo Politechniki Śląskiej, 1999 Gliwice (in Polish).

[5] RWTÜV Replicas for parts under creep according to TRD 508. Recommendation, 451-1983/1, 1983

[6] S. Webster, A. Bannister, Structural Integrity Assessment Procedure for Europe - of the SINTAP programme overview, Engineering Fracture Mechanics, Elsevier Science 67, 6, 481-514 (2000).

[7] A.G. Miller, R.A. Ainsworth, A.R. Dowling and A.T. Stewart Background to and validation of CEGB report R/H/R6 - version 3. Int. J. Pres. Vessels Pip. 32, 105-196 (1988).

[8] K.M. Nikbin, G.A. Webster, C.E. Turner, A Comparison of Methods of Correlating Creep Crack Growth, Fracture 2, 1977.

[9] A.J. Fookes, D.J. Smith Using a Strain Based Failure Assessment Diagram for Creep-Brittle Materials, 2th International HIDA Conference, 2000 Stuttgart.

[10] S.S. Manson, G.R. Halford, Fatigue and durability of materials at high temperatures, ASTM International (2009).

[11] S.S. Manson, G.R. Halford, Fatigue and durability of structural materials. ASTM International (2006).

[12] S.S. Manson, Thermal Stress and Low Cycle Fatigue, 1966 New York: McGraw-Hill.

[13] S. Kocańda, J. Szala, The basics of fatigue calculations (Podstawy obliczeń zmęczeniowych - in Polish), PWN Warszawa 1997.
[14] M.R. Mitchell, R.W Landgraf (eds.), Advances in fatigue lifetime predictive techniques, ASTM STP 122, 1991.

[15] Z.W. Huang, Z.G. Wang, S.J. Zhu, F.H. Yuan, F.G. Wang, Thermomechanical fatigue behavior and life prediction of a cast nickel-based superalloy, Materials Science and Engineering A 432, 308-316 (2006).

[16] W.J. Ostergren, Damage function and associated failure equations for predicting hold time and frequency effects in elevated temperature, low cycle fatigue, J. Test Eval. 4 (5), 327-339 (1976).

[17] J. Schijve, Fatigue of Structures and Materials in the 20th Century and the State of the Art, Proceedings of ECF 14 Conference: "Fracture Mechanics Beyond 2000, Kraków, 211-262 (2002).

[18] PN-EN 12952-4:2002.

[19] J. Bressers, L. Remy (eds.), Fatigue under Thermal and Mechanical loading. Netherlands: Kluwer Academic Publishers 1996.

[20] P. Hähner, C. Rinaldi, V. Bicego, E. Affeld, T. Brendel, H. Andersson, T. Beck, H. Klingelhöffer, H-J Kühn, A. Köster, M. Laveday, M. Marchionni, C. Rae, Research and development into a European code-of-practice for strain-controlled thermo-mechanical fatigue test, International Journal of Fatigue 30 (2), 372-381 (2008).

[21] H. Sehitoglu, Thermal and Thermo-mechanical Fatigue of Structural Alloys, In: Fatigue and Fracture ASTM Handbook 19, 527-556 (2008).

[22] J. Okrajni, M. Plaza, Simulation of the fracture process of materials subjected to low-cycle fatigue of mechanical and thermal character, Journal of Material Processing Technology 53, 311-318 (1995).

[23] J. Okrajni, G. Junak, A. Marek, Modelling of the deformation process under thermo-mechanical fatigue conditions, International Journal of Fatigue 30 (2), 324-329 (2008).

[24] A. Marek, J. Okrajni, G. Junak, M. Twardawa, Research on dependence between the fatigue life of X20CrMoV12.1 and P91 steels under conditions of interactions of thermo-mechanical and isothermal low-cycle fatigue, Solid State Phenomena 224, 93-98 (2015).

[25] G. Junak, M. Cieśla, Low-cycle fatigue of P91 and P92 steels used in the power engineering industry, Arch. Mater. Sci. Eng. 48 (1), 19-24 (2011). 